\title{
Notas Sobre a Presença de Mead na OBRa de Habermas
}

\author{
Luciana Aparecida de Araújo Penitente ${ }^{l}$
}

\begin{abstract}
RESUMO: Habermas pensa a questáo da individuação e da socialização a partir dos estudos de George Hebert Mead, que, na sua concepção, foi o primeiro a refletir substancialmente sobre um modelo de eu produzido socialmente. Mead oferece todo subsídio teórico para o desenvolvimento de uma teoria da evoluçáo humana que envolve o processo de individuação e de socialização. Pelo paradigma de intercompreensão, ou seja, da relação intersubjetiva de indivíduos que se socializam por meio da comunicação e se reconhecem mutuamente, Mead permite a mudança de paradigma da consciência de si, da autorreferência de um sujeito que age isoladamente para o indivíduo que processa trocas sociais mediante a linguagem. Portanto, um dos principais componentes da teoria de Mead, em que Habermas busca contribuição para sua Teoria da Ação Comunicativa, é o processo de constituição do "eu", sua identidade. Mead acredita ser a individuaçáo representada como um processo que é linguisticamente mediador da socialização e da construção de uma história de vida, na qual os sujeitos são conscientes de si. É esse meio linguístico estabelecido entre os sujeitos e o meio do entendimento intrassubjetivo e histórico vital que possibilita a formação de uma identidade de sujeitos socializados. É o reconhecimento intersubjetivo e autoentendimento mediado intersubjetivamente que propicia a formação da identidade. Esse quadro conceitual será fundamental a Habermas, na sua acepção de eu pós-convencional.
\end{abstract}

PALAVRAS-CHAVE: Identidade. Linguagem. Interaçẫo Sociolinguística. Individuação. Socialização.

O homem, tomado como IDENTIDADE, não apenas vive, mas convive. Nessa perspectiva, dizer PESSOA é construir um entrelace ou nós de relaçóes, alianças, intercâmbios que tornam os homens responsáveis uns face aos outros, realizando-os, frustrando-os... O eu pessoal patenteia-se sempre habitado e comprometido com os outros. Essa rede de inter-relaçôes apenas

\footnotetext{
${ }^{1}$ Possui Doutorado em Educação pela UNESP “Júlio de Mesquita Filho" e Pós-Doutorado pela Fundação Carlos Chagas (2013). É professora Assistente Doutora do Departamento de Didática da Faculdade de Filosofia e Ciências, UNESP de Marília.
} 
se constrói pelo uso da linguagem e se permeia de princípios morais, por meio dos quais se instalam sempre novos comportamentos de comunicação. Comunicar-se significa estar face a face com o diferente. No encontro, ou no confronto do Eu com o Eu diferente de outrem, é que se dá a comum + uniáo, ou comunhão - a comunicação. Apenas sei o que é a minha pessoa quando conheço a pessoa do outro. Da interação cumulativa $E U+T U=N O ́ S$ resulta a comunicação, o equilíbrio nas inter-relaçóes pessoais. Nos contatos com o outro, busca-se compreensão, persegue-se o viver em comunidade comungando as mesmas ideias, sonhos, sentimentos, emoçóes, objetivos etc. Onde há comunicação, aí se edifica a identidade da pessoa, e há aprovação social (ARAÚJO, 2005).

A partir dessas pressupostas consideraçóes iniciais, este texto pretende salientar, ainda que brevemente, alguns fundamentos discutidos por George Herbert Mead - tais como: o fazer-se pessoa, a questão do "eu" e do "me", a conquista da individuação e socialização - que trouxeram contribuiçôes aos estudos a respeito da comunicação, ética, linguagem e interação realizados por Jürgen Habermas.

Para a filosofia da linguagem, o homem apenas compreende e age no mundo quando consegue atribuir-lhe sentido. Tal premissa implica que os sujeitos tenham uma participação ativa, de modo a buscar compreender qual é o seu papel neste mundo.

Esse novo contexto filosófico propóe uma análise de comportamento, que vai desde o uso pragmático das expressóes linguísticas até a comprovação intersubjetiva das pretensóes levantadas por cada pessoa, na inter-relação. Dessa maneira, o sujeito se coloca numa relação interpessoal que o possibilita relacionarse consigo mesmo com base na perspectiva do outro. Sendo assim, os sujeitos têm de assumir o enfoque performativo de um falante, que procura entender-se com uma segunda pessoa sobre algo no mundo (cf. HABERMAS, 1990).

Habermas denomina "mundo da vida", ou mundo vivido, o lugar onde esse processo de individuação ocorre. No mundo da vida, a cultura, a personalidade e a linguagem encontram-se interligadas, entrelaçam-se, reproduzem-se e se manifestam linguisticamente. Nele há sentido, diálogo, troca e emoção. Trata-se de um mundo compartilhado intersubjetivamente pelos sujeitos. Como o processo de individuação nasce e se desenvolve no mundo da vida, ele deve ter uma implicação ética necessária de socialização e uma interação a ela. 
Para Habermas, tanto o processo de individuaçáo quanto o de socialização desenvolveram-se e evoluíram com a espécie humana. Trata-se de processos complementares um do outro, de modo que, à medida que acontece a socialização, se desenvolve também a individuação.

\section{I}

Habermas pensa a questão da individuação e da socialização a partir dos estudos de George Herbert Mead, que, na sua concepção, foi o primeiro a refletir substancialmente sobre um modelo de eu produzido socialmente. Para Habermas, Mead oferece o subsídio teórico necessário para o desenvolvimento de uma teoria da evoluçáo humana que envolve o processo de individuação e de socialização, permitindo a mudança de paradigma da consciência de si, da autorreferência de um sujeito que age isoladamente pelo paradigma de intercompreensão, ou seja, da relação intersubjetiva de indivíduos que se socializam por meio da comunicação e se reconhecem mutuamente.

Do ponto de vista dos sujeitos atingidos, Habermas (1990, p. 217) afirma que o processo de individuação social possui dois aspectos diferentes. Tanto no nível cultural como no institucional, eles passam a ser cobrados por uma conduta consciente e por uma autonomia. Os padróes culturais e as expectativas de uma autorrealização e de uma autodeterminação também mudam, à medida que as atençóes passam a voltar-se para as suas próprias realizaçóes. Em se tratando da questão moral e ética, segundo propóe a psicanálise, a formação convencional da identidade se rompe devido à diferenciação social, à diversidade de expectativas de papéis conflitantes, à instância da consciência que se distanciam do ideal-eu. O Selbst, que fica sobrecarregado com suas próprias realizaçóes, constitui-se por meio da sociedade e, desde o momento em que o indivíduo se direciona para uma sociedade mais abrangente, ele recorre aos outros sujeitos, na hipótese de que estes reagirấo ao seu apelo. Nesse momento, ocorre uma oposição das atitudes do "I" em relação às atitudes do "me".

Um dos principais componentes da teoria de Mead, em que Habermas busca contribuição para sua Teoria da Açáo Comunicativa, é o processo de constituição do "eu", sua identidade. 
A identidade é, para Habermas (1990, p. 204-6) algo que não pode ser assumido pelo sujeito como propriedade sua, não depende apenas de seu poder, pois o Selbst da autocompreensão ética não é algo de posse interna do sujeito: depende do reconhecimento através dos destinatários, já que, inicialmente, se configura como uma resposta dada à exigência de alguém que está à sua frente. O "eu" é dado ao sujeito em sua autoconsciência como sendo um "eu" puro e próprio. No entanto, ele não pertence ao sujeito, porque é um "eu" que contém um núcleo intersubjetivo, uma vez que o processo de individuação, do qual surge, se dá por meio das interaçóes mediadas pela linguagem. Para ele, Mead rompe com esse círculo de reflexão auto-objetivadora, propondo a passagem para o paradigma da interação que é mediada simbolicamente.

Nesse paradigma, a subjetividade, enquanto pensada como um espaço interior em que se dão as representaçóes próprias de cada sujeito, abre-se ao sujeito representador de objetos, voltando-se para sua atividade de representação. Desse modo, tudo aquilo que é subjetivo só pode ser acessível na forma de objetos de auto-observação ou da introspecção, inclusive o próprio sujeito, que participa dessa contemplação como um "me" objetivado. "O Selbst, que está conscientemente perante o Selbst de outros, torna-se, pois, um objeto, um outro em relaçáo a si mesmo pelo fato de se ouvir falar e de dar respostas a si mesmo" (MEAD, s/d., p. 244 apud HABERMAS, 1990, p. 206).

Habermas acredita ser a psicologia social de George Herbert Mead a única e promissora tentativa de apreender conceitualmente o conteúdo cheio de significado da individualização social, já que Mead apresenta a diferenciação da estrutura de papéis frente à formação da consciência e à obtenção da autonomia de sujeitos que se tornam socializados em diferentes situaçóes. Hegel coloca a individuação como dependente da subjetivação crescente do espírito, enquanto Mead a concebe como resultado da internalizaçáo das instâncias que controlam o comportamento e que, de certa forma, imigram de fora para dentro. À medida que o processo de socialização possibilita o crescimento do sujeito, este incorpora tudo aquilo que as pessoas de sua referência esperam dele.

Em seguida, os sujeitos começam a integrar e até a generalizar as expectativas múltiplas e também as contraditórias, dando início a um centro interior de autocomando do comportamento. Essa instância de consciência representa um grau de individuação que requer uma certa diferenciação de papéis, ocorrendo, quando, no percurso da vida, o sujeito se depara com situaçôes conflitantes. É a individuação do "si mesmo" (Selbst): consequência 
do número do alcance e da variedade das açóes autônomas que o sujeito inicia e que lhe são colocadas de forma normativa. Habermas acrescenta que Mead imagina ser a individuação representada como um processo linguisticamente mediador da socialização e da construção de uma história de vida, na qual os sujeitos se tornam conscientes de si. É esse meio linguístico estabelecido entre os sujeitos e o meio do entendimento intrassubjetivo e histórico vital que permite a formação de uma identidade de sujeitos socializados. É o reconhecimento intersubjetivo e o autoentendimento mediado intersubjetivamente que propiciam a formação da identidade.

Mead conseguirá realizar esse pensamento ao passo que se reduz a instância "eu" da filosofia da consciência a um "me", ou seja, a um Selbst que se coloca apenas em situaçóes de interação, sob os olhos de um Alter, retirando todos os conceitos da filosofia da base da consciência e transportando-os para a linguagem.

O Selbst da relação prática certifica-se de si mesmo por meio do reconhecimento de suas pretensôes por parte de um Alter ego. Essas pretensóes de identidade, desprovidas de reconhecimento intersubjetivo, não podem se confundir com as pretensóes de validez colocadas pelos sujeitos, durante um ato de fala. Quando um sujeito pede ao outro que tome uma posição em relação à sua fala, ele está reconhecendo que o outro é um ator responsável. É isso que propóe o agir comunicativo: que cada sujeito possa reconhecer a própria autonomia no outro.

No mundo da vida compartilhado intersubjetivamente, os contextos normativos determinam a quantidade de todas as referências interpessoais reconhecidas como legítimas. Numa relação interpessoal, o falante referese a uma rede de expectativas normativas. Contudo, enquanto as interaçóes estiverem estruturadas linguisticamente, o preenchimento de papéis sociais não pode significar simplesmente a reproduçáo deles. Aquele que age de maneira comunicativa é levado pela própria estrutura da subjetividade linguística a continuar sendo ele mesmo. No agir orientado por normas, nenhuma pessoa poderá tirar da outra a iniciativa de realizar simultaneamente a si mesmo, e também não se poderá deixar de lado essa iniciativa. Dessa forma, Mead continua sublinhando que "[...] o momento da não-previsibilidade e da espontaneidade está no modo como o ator representa inevitavelmente seus papéis. $\mathrm{O}$ efeito de individuação do processo de socialização, mediado através da linguagem, explica-se pelo próprio meio lingüístico" (HABERMAS, 1990, p. 225). 
As discussóes realizadas em torno do conceito da individualidade voltam-se para a necessidade de esclarecimento desse conceito, partindo da ideia de autocompreensão de um sujeito que é capaz de falar, agir e se justificar, diante dos outros participantes do diálogo, como alguém inconfundível. Nessa autocompreensão, a autoconsciência se articula como a autocertificação ética de uma pessoa imputável.

\section{II}

Nesse contexto da linguagem, Habermas (1990, p. 222-3) estabelece que o "eu" ocupou-se de dois papéis gramaticais. De um lado está o "eu" como expressão autorreferencial, quando o falante se coloca em oposiçáo a um ouvinte como sendo uma entidade que se póe em meio à quantidade de todos os possíveis objetos. De outro, está o "eu" enquanto papel gramatical desempenhado pela primeira pessoa em proposiçóes vivenciais, em que essa expressão possibilita ao falante entrar em contato com o mundo subjetivo próprio. $\mathrm{O}$ tema é a autorreferência epistêmica em ações nas quais ocorrem falas expressivas. O Selbst da autorrelação prática só é avistado quando se analisa o papel gramatical que a primeira pessoa assume em proposiçóes performativas, enquanto expressão própria do sujeito. Assim, o "eu" assume o papel de ator de uma açáo de fala e, num enfoque performativo, estabelece uma relação interpessoal com a segunda pessoa. No contexto performativo, o "eu" representa uma função de qualquer ato ilocucionário. Nesse "eu", a expressão se refere ao falante, como ele realiza um ato ilocucionário e se coloca em confronto com uma segunda pessoa, enquanto Alter ego. Por conseguinte, o falante não pode referir-se in actu a si mesmo como falante, se não assumir a perspectiva do outro, e não pode descobrir-se a si mesmo, a não ser como segunda pessoa de uma segunda pessoa. O significado do "eu" é o "me" de Mead, que deve acompanhar todos os atos de fala do sujeito. Mead ainda insistiu que a referência à segunda pessoa é inevitável para qualquer autorreferência, inclusive para a epistêmica.

Mead será o primeiro a considerar o enfoque performativo da primeira pessoa em relação à segunda e principalmente, a relação tu-me, como elemento para a sua crítica em relação à autorelação do sujeito que objetiva a si mesmo. Ele refere-se também a uma passagem para a moral convencional e a vê como um momento em que "produz-se uma comunidade de comunicaçáo ilimitada que transcende a ordem particular 
de uma sociedade determinada, no interior da qual os membros são capazes de sair da sociedade existente, quando se dá um conflito particular, a fim de buscar um consenso sobre costumes modificados de ação e uma nova formulação de idéias de valor”. (MEAD, Obras, 1980, v. I, p. 413 apud HABERMAS 1990, p. 218-9).

Desse modo, atribui-seà formaçáo do juízo moral e do autoentendimento ético uma razão que leva à socialização do sujeito, temporalizando, assim, a razão prática. Para Habermas, Mead acaba concretizando e dinamizando a esfera pública universalizada de Rousseau e o mundo inteligível de Kant. Daí Habermas, apoiado em Mead, considerar que a forma idealizada de comunicação deve assegurar ao processo discursivo da formação da vontade um momento de incondicionalidade.

Com respeito a essa questão do princípio da teoria moral, Mead foi mais adiante do que concebê-lo apenas como um princípio de ética, uma vez que esta deveria apresentar o conceito de autorrealização no mesmo enquadramento de uma teoria da comunicação. A diferenciação de identidades singulares e o crescimento da autonomia pessoal conduzem ao crescimento do processo de individuação. Dessa maneira, Mead insiste em entrelaçar o processo de individuação com o de socialização, pois o fato de que todo Selbst

[...] se forma por meio do processo social, sendo sua expressão individual... é facilmente combinável com o fato que todo o Selbst particular tem uma individualidade própria e específica... porque todo o Selbst particular forma sua posição própria e singular no interior desse processo, enquanto reflete suas estruturas organizadas de comportamento (precisamente como as mônadas do universo leibniziano, cada uma das quais reflete esse universo a partir de um outro ângulo). (MEAD, 1973, p. 210-1, traduçáo nossa).

Nos dizeres acima, Mead enfatiza que o indivíduo classifica os acontecimentos comuns na vida da comunidade sob um aspecto que se diferencia do ponto de vista de qualquer outro sujeito. Em decorrência, para Habermas (1990, p. 220-221), o Selbst da autorrelação prática não pode certificar-se de si mesmo numa reflexão direta, pois necessita sempre partir das expectativas do outro. Nesse momento, entra em jogo o processo de idealizaçáo, em que se refere tanto à comunidade ilimitada de comunicação como também a própria pretensão de individualidade dos sujeitos. É o momento quando cada um pode assumir a perspectiva de cada um dos 
outros; e cada sujeito pode contar com o reconhecimento recíproco de todos, permitindo a socialização de sujeitos individualizados. A proposta de uma sociedade projetada possibilita levar com seriedade a própria história de vida como princípio da individuação.

$\mathrm{Na}$ ação comunicativa pressuposta nesse entendimento está contido o processo de individuação e socialização. A competência comunicativa é, desse modo, a capacidade do indivíduo de manejar adequadamente as pretensóes de validade contidas em sua fala (retidão, inteligibilidade, verdade, veracidade) e, com isso, a formação de seu "eu": aquela competência que propicia uma atuação no mundo da vida de forma cada vez mais autônoma, consciente e interativa.

\section{III}

$\mathrm{Na}$ interação mediada por gestos, assim proposta por Mead, Habermas (1990, p. 207) destaca que, quando são utilizados em situaçóes comunicativas, com uma intençáo comunicativa e com expressóes linguísticas, esses gestos traem, no sentido de uma relação intencional do sujeito consigo mesmo, antes que se possa atribuir-lhes a autorrelação refletida "[...] de um diálogo deslocado para dentro". ${ }^{2}$

Na visão de Habermas (1990, p. 210), existem duas condições necessárias já apresentadas por Mead para que a interação mediada por gestos possa converter-se numa interação mediada simbolicamente; primeiramente, o gesto precisa se transformar em um símbolo, através da substituição dos significados que só valem para cada um dos organismos em particular, por significados idênticos adotados por toda a comunidade linguística. Além disso, é necessária uma transformação no comportamento dos sujeitos envolvidos na interação, substituindo-se a relação estímulo-reação-estímulo pela relação interpessoal instaurada entre um emissor e um destinatário que buscam uma comunicação.

Nesse contexto, Habermas, em sua Teoria da Ação Comunicativa, propóe uma terceira condição para a evolução da competência comunicativa: é necessário que ocorra uma mudança estrutural da interação, de sorte que os participantes da comunicação aprendam a diferenciar atos de entendimento e atos com respeito-a-fins, pois tanto a formação quanto o processo de desenvolvimento do "eu" acontecem por meio da articulação de três competências: cognitiva,

${ }^{2}$ Ver em MEAD, Obras, v. I, p. 245 apud HABERMAS, 1990, p. 207. 
interativa e comunicativa, que, ao se desenvolverem e se articularem, devem conduzir ao desdobramento do "eu" e à formação de uma identidade capaz de proporcionar a integração social e a autonomia do "eu".

Habermas busca na antropologia de Mead e na sociologia de Durkheim os fundamentos e os processos constitutivos da norma social. Para ele, "[s]er uma pessoa significa ser uma fonte autônoma do agir. O homem só adquire essa qualidade à medida que possui algo em si mesmo, que o individualiza, onde ele é mais do que uma simples encarnação do tipo especial de sua raça e de seu grupo" (DURKHEIM, 1977, p. 444 apud HABERMAS, 1990, p. 184).

Os padrốes de comportamento se desenvolvem com base em um processo de interiorizaçáo das expectativas do comportamento que um indivíduo vivencia, no período da infância, em relação a pessoas de sua referência. Segundo Mead, essas expectativas representam o ponto de partida do desenvolvimento da socialização do sujeito e da construção de um mundo social da criança.

O desenvolvimento da competência interativa fundamentada na norma permite que ocorra um processo de interação e integração social que tem suas bases fixadas no consenso. A competência comunicativa mediante a fala proposicional e argumentativa permite transformar o consenso alcançado pela convencionalidade da norma em um consenso alcançado por meio da interação fundamentada no entendimento e pautado pela discussão argumentativa. Essa transformação que se dá no processo constitutivo do consenso representa, para Habermas, a passagem de uma interação social, caracterizada por uma normatividade convencional, a uma normatividade pós-convencional.

\section{IV}

O "me" representa o meio por que a criança, ao adotar diante de si mesma as expectativas do "outro generalizado", se provê de condiçóes de construir um sistema de controles internos de comportamentos. Nessa perspectiva, essa interiorização de papéis sociais cria uma estrutura de superego (MEAD, 1934, p. 174) que vai se tornando cada vez mais integrada, de modo a facultar ao sujeito orientar-se pelas pretensóes normativas de validez. Ao mesmo tempo em que se constitui esse superego, ou seja, o "me", formamse também o "eu" ou o "I", que passam a representar o mundo subjetivo 
das vivências. Segundo a interpretação de Habermas (1987b, p. 62), Mead acredita que, nessa instância, os desejos, os sentimentos, os estados de ânimos transcorrem de maneira espontânea, como um potencial de reaçôes em que se descarregam as orientaçóes ancoradas no superego e que constituem, diante do mundo externo, o âmbito do subjetivo.

Com relação ao "I", Habermas acha que ele representa, na estrutura do "eu", a tendência para afirmar com espontaneidade as vivências e conteúdos da subjetividade. O "I" busca inovação e, por esse motivo, corresponde a um desejo de liberdade. É uma instância que se separa daquilo que é convencional nas normas e procura colocar o "eu" além do indivíduo institucionalizado. Mead entende o "I" como "[...] a capacidade generalizada de encontrar soluções criadoras para situaçóes em que está em jogo algo assim como a autorealização da pessoa" (HABERMAS, 1987b, p.63).

Sob essa óptica, o "I" é uma tendência à não-conformidade, à busca da autonomia e da individuaçáo. No entanto, cabe lembrar que tanto o "me" quanto o "I" são tendências opostas dentro da estrutura do "eu", embora se articulem entre si, uma vez que, sem o "me", náo seria possível o processo de socialização e, na ausência do "I", não seria possível o processo de individuação. A compreensão da relação entre o "eu" e o "me" é considerada por Habermas um ponto chave tanto para a compreensão do "eu" socialmente produzido, conforme proposto por Mead, quanto para o desenvolvimento ulterior de sua temática da individuação e socialização.

A correspondência entre instituições sociais e controles do comportamento, no sistema da personalidade, é esclarecida também por Mead e, para isso, ele se utiliza do mecanismo da perspectiva de um outro que assume em relação ao Ego, num enfoque performativo. Nesse momento, ocorre a assunção de papéis:

Ego assume as expectativas normativas de Alter, não as cognitivas. $\mathrm{O}$ processo conserva a mesma estrutura. Pelo fato de eu me apreender como um objeto social de um outro, forma-se novamente uma instância reflexiva, através do qual Ego apropria-se de expectativas de comportamento de outros. Ora, ao caráter normativo dessa expectativa corresponde, de um lado, uma estrutura modificada desse segundo " $M e$ " e, de outro lado, uma outra função da autoreferência. O "Me" da auto-relação prática não é mais a sede de uma auto-consciência originária ou refletida, mas a instância do autocontrole. A autoreflexão assume aqui a tarefa específica de mobilizaçáo de motivos de açáo e de controle interior dos próprios modos de comportamento. (HABERMAS, 1990, p. 213). 
O "me" é interpretado por Mead como o "generalized other", isto é, o outro generalizado e, nos dizeres de Habermas (1990, p. 213-6), isso explica como as expectativas de comportamento do ambiente social - que são generalizadas normativamente - imigram para dentro da pessoa. Diante dessa instância, o "I" se coloca como espontaneidade retirada da consciência e, ao contrário do "eu" epistêmico, o "eu" prático forma um inconsciente que se torna perceptível de duas maneiras, a saber: como afluência dos impulsos controlados e como fonte das inovaçóes que rompem e renovam os controles cristalizados de modo convencional. A autorreferência epistêmica pode se tornar possível por meio de um "me", que não só retém na memória o "eu" que age espontaneamente, como também se apresenta no enfoque performativo de uma segunda pessoa. A autorrelação prática torna-se possível através de um "me", que coloca obstáculos à impulsividade e à criatividade de um "eu" resistente, na perspectiva intersubjetiva do nós social.

Mead afirma que o outro generalizado de sua experiência lhe empresta uma identidade-eu. Essa colocação de Mead em relação ao funcionamento dessa identidade-eu conduz à compreensão acerca do porquê de ele não a identificar como sendo o Eu.

Nós nos louvamos e nos censuramos a nós mesmos. Nós mesmos nos batemos no ombro e, cheios de ira cega, batemos em nós mesmos. Ao censurarmos nossas idéias e monólogos e ao afirmarmos as regras gerais e princípios de nossa comunidade de comunicação, assumimos o enfoque generalizado do grupo. (MEAD, 1973, p. 323).

O "me" carrega uma consciência moral que aspira ao que é de costume às práticas de um determinado grupo particular. Representa, na verdade, o poder de uma certa vontade coletiva sobre um elemento individual que ainda não atingiu a si mesmo. Caracteriza uma formação de identidade que possibilita o agir responsável. Segundo Habermas (1990, p. 216), a identidadeeu convencional é o lugar-tenente da verdadeira. Por esse motivo, mesmo em se tratando da autorrelação prática, Mead não pôde retirar a diferença existente entre "I" e "me".

De acordo com o pensamento habermasiano, Mead descreve o Selbst da autoconsciência como o objeto social que se relaciona às feiçóes que o sujeito identifica em si mesmo no processo comunicativo, quando ele entra em contato com a relação tu-me e ao descobrir-se como um Alter-ego de seu próprio Alter-ego, nesse processo comunicativo. Na primeira pessoa, ele 
se defronta com o seu próprio enfoque performativo como segunda pessoa. Quando isso ocorre, surge então um "me" que é inteiramente diferente. Não coincide tampouco com o "I", que é o "eu" agindo espontaneamente, de onde se tira qualquer experiência direta. Esse "me" alcançado no enfoque performativo surge como uma recordação exata de um estado espontâneo do "eu", que pode ser reconhecido de forma não dissimulada, a partir das relações da segunda pessoa. "O Selbst que me é dado através da mediação do olhar do outro sobre mim, é a 'imagem de recordação' de meu Ego, do modo como ele há pouco agiu em face de um Alter ego” (HABERMAS, 1990, p. 206).

O "me", então, deve ser evidenciado pela perspectiva de um Alter ego e pode apenas esclarecer a autoconsciência como um fenômeno originário se estiver situado em um contexto de competência lingüística utilizada para monólogos internos. [...] (HABERMAS, 1990, p. 207)

Por conseguinte, Mead estabelece que, se quisermos utilizar símbolos com significado idêntico, então obrigatoriamente devemos pressupor a autoconsciência. Assim, é preciso rever quais foram as fontes de Mead. Habermas declara que, nos primeiros trabalhos, Mead, se apoiou na ideias de John Dewey, com o objetivo de alcançar, através do "me" reificado da psicologia positivista, o "eu" como fonte de realizaçóes espontâneas. A princípio, Mead procurou encontrar um acesso ao mundo subjetivo e, para tanto, empregou o conceito pragmatista da problematização de uma interpretação da situação, anteriormente usada por Peirce.

Um "problema" estorva as execuçốes de um plano de ação empreendido, subtrai a base de validade de uma expectativa até entáo comprovada e provoca um conflito dos impulsos da ação. Nesta fase da desintegração, implode em si mesmo aquilo que nós tínhamos aceitado como objetivo: 'nossos objetivos são expulsos de sua posição objetiva e desterrados para um mundo subjetivo'. O segmento do mundo tornado problemático é espoliado de sua familiaridade e validez, no interior de um horizontede-mundo que permaneceu intacto; ele resta como o material das representaçôes puramente subjetivas e forma a matéria da qual é feito o "elemento psíquico". (HABERMAS, 1990, p. 207-8). 


\section{V}

No que concerne à autoconsciência, tem-se que ela ocorre por meio de uma relação a qual se mantém com o outro e que é simbolicamente mediada. Dá-se de fora para dentro, permitindo que a autoconsciência tenha um núcleo intersubjetivo.

Segundo Habermas (1990, p. 212-3), esse posicionamento coloca a subjetividade numa condição de dependência perante a linguagem, ou seja, diante do meio que permite ao sujeito reconhecer-se no outro de modo não objetivador.

$\mathrm{Na}$ ótica habermasiana, Mead negligencia a distinção entre a autorrelação originária que prepara o trânsito da comunicaçáo mediada por gestos sonoros a uma comunicação a que Habermas chama de linguisticamente genuína, além da autorrelação refletida que se produz apenas por meio do diálogo consigo mesmo.

Habermas acredita que somente esta pode desvendar o campo dos fenômenos das representaçóes de que a filosofia do sujeito parte como um elemento único, desde a época de Descartes, sugerindo que essa imprecisão possa revelar os pontos falhos da filosofia da linguagem de Mead. Além disso, pensa ter-se tornado obscura a distinção entre autorreferência epistêmica do sujeito cognoscente e a sua autorrelação prática. Ressalta ele que Mead não apresenta essa diferença, talvez porque ele entenda o "conhecer" como a prática que pode levar à solução de problemas e a autorreferência cognitiva como uma função do agir. Essa autorrelação prática é explicada por Mead de forma semelhante ao que ele faz em relação à autorreferência epistêmica, ou seja, por meio de uma reorganização do nível de interação pré-linguística comandada pelos instintos; ela surge da passagem para um outro modo de comunicação, ao passo que a anteriormente citada resulta da passagem para um outro mecanismo de controle de comportamento. Essas reorganizaçóes propiciam a diferenciação dos dois aspectos da coordenação do comportamento que coincidem no modelo de uma reação instintiva desencadeada por meios de estímulos próprios à espécie.

A interação mediada simbolicamente permite um comando cognitivo auto-referencial do próprio comportamento; esse, no entanto, náo é capaz de substituir a ação de coordenação que até então era assegurada através de um repertório comum de instintos, portanto, através do engate 'adequado' das ações de um dos atores nas do outro. Esse vácuo é preenchido por 
expectativas de comportamento generalizadas normativamente, que entram no lugar da regulação instintiva; só que essas normas necessitam de uma ancoragem no sujeito agente através de controles sociais mais ou menos internalizados. (HABERMAS, 1990, p. 213).

\section{VI}

A respeito dos processos de formação da personalidade e da socialização, Habermas observa que, para Mead, a pessoa se torna uma personalidade por participar de uma comunidade e adotar a linguagem desta como um medium, por cuja ajuda desenvolve sua personalidade. E, posteriormente, dados os diferentes papéis que vão sendo propostos por todos os outros membros da comunidade, a pessoa acaba adotando a mesma atitude da comunidade. Nessa perspectiva, Habermas discorda de alguns pontos da teoria proposta por Mead, porquanto considera inadequada a denominação de "behaviorismo social”, que o próprio Mead dá à sua teoria, uma vez que o modelo do qual parte Mead não é o comportamento de um organismo individual que reage aos estímulos à sua volta, mas a interação na qual ao menos dois organismos reagem um ao outro (HABERMAS, 1987, p. 11). Além disso, entende que Mead confere muita importância aos efeitos que o grupo social produz na personalidade e na conduta do sujeito. E, diferentemente de Mead, atribui uma importância semelhante à influência do social no individual e vice-versa, afirmando que isso ocorre simultaneamente por intermédio da linguagem.

Habermas parece criticar Mead por não ter dado mais atenção para alguns pontos cruciais da estrutura interna da linguagem, como a dupla estrutura performativo-proposicional da linguagem (HABERMAS, 1987, p. 38-45) e as quatro pretensóes de validade intersubjetiva levantadas em todo ato de fala.

Uma outra crítica reside na maneira como Mead concebe a comunicação linguística, na medida em que ele privilegia os aspectos de coordenação da ação e de socialização dos sujeitos e se esquece de explorar a questão da função do entendimento apresentada pela linguagem. Para Habermas, Mead atenta para a linguagem enquanto medium que possibilita a coordenação da ação e o processo de socialização, sem dar a importância necessária à linguagem como medium que facilita o entendimento entre os sujeitos. Apesar de Mead quase não levar em conta este último aspecto, Habermas acredita ser possível implantar 
um processo de entendimento na teoria do autor, já que ele considera que só existe comunicação entre dois sujeitos participantes de uma interação qualquer se eles entendem e utilizam um símbolo com o mesmo significado. Para Habermas, a linguagem em Mead consiste em

[...] um medium, náo do entendimento e da transmissáo do saber cultural, mas sim da socialização e da interação social. Estas têm lugar, por certo, mediante atos de entendimento, mas diferentemente do que acontece com os processos de entendimento, não se sedimentam no saber cultural e sim em estruturas simbólicas do "si mesmo" (self) e da sociedade, em competências e em padróes de interação. (HABERMAS, 1987b, p. 40, traduçáo nossa).

A partir das consideraçóes expostas nos parágrafos anteriores, podese perceber que divergências entre Mead e Habermas acerca da comunicação inclusive acontecem na medida em que Mead vê na comunicaçáo linguística o aspecto de interação social e o de socialização dos indivíduos, enquanto Habermas toma o entendimento como mantenedor e renovador do saber cultural. Nessa perspectiva, Habermas observa que o entendimento entre os sujeitos acerca do significado das palavras e das coisas no mundo torna possível a interaçáo social destes com o mundo da vida, uma vez que as situaçóes de fala influenciam na manutenção e na renovação do saber cultural, dado que o mundo da vida oferece o contexto propício para os processos de entendimento em geral. 
PENITENTE, Luciana Aparecida de Araújo. Notes on Mead's presence in the work of Habermas. Trans/Form/Ação, Marília, v. 36, p. 205-220, 2013. Edição Especial.

\begin{abstract}
Habermas discusses the question of individualization and socialization on the basis of the studies of George Herbert Mead, who, in Habermas' view, was the first to reflect substantially on a model of the socially produced "I". Mead offers a theoretical basis for the development of a theory of human evolution that involves the process of individualization and socialization. Through the paradigm of mutual understanding, that is, the intersubjective relationship of individuals who are socialized through communication and mutual recognition, Mead allows for a change in the paradigm of self-consciousness, from the self-reference of a subject who acts in isolation to the individual who processes social exchanges through the language. Therefore, one of the major components of Mead's theory in which Habermas seeks a contribution for his theory of communicative action, is the process of constitution of the "I," the subject's identity. Mead believes that individualization is represented as a process that is linguistically the mediator of socialization and of the construction of a life story in which subjects are aware of themselves. It is this linguistic means, established between the subjects and their means of intra-subjective understanding and their life histories, that allows the formation of an identity of socialized subjects. It is the intersubjective recognition and intersubjectively mediated self-understanding that enables identity formation. This conceptual framework will be central to Habermas in his concept of the self post-conventional "I".
\end{abstract}

KEYWORDS: Identity. Language. Social Linguistic Interaction. Individuation. Socialization.

\title{
REFERÊNCIAS
}

ARAÚJO, L. A. de. A linguagem e a moralidade na constituição do eu. 2005.234f. Tese. (Doutorado em Educação) - Faculdade de Filosofia e Ciências, Universidade Estadual Paulista, Marília, 2005.

HABERMAS, J. Pensamento Pós-metafísico: estudos filosóficos. Rio de Janeiro: Tempo Brasileiro, 1990, 271p.

. Teoria de la acción comunicativa. Racionalidad de la acción y racionalización social. 4. ed. Trad. Manuel Jiménez Redondo. Tomo I, Taurus, 1987a .

Teoria de la acción comunicativa. Crítica de la razón funcionalista. 1. ed. Trad. Manuel Jiménez Redondo. Tomo II, Taurus, $1987 \mathrm{~b}$.

MEAD, G. H. Espiritu, Persona y Sociedad: desde el punto de vista del conductismo social. Buenos Aires: Paidós, 1973, 393p.

. Mind, self and society. Chicago: University of Chicago Press, 1934. Disponível em: http://www2.pfeiffer.edu/-Iridener/DSS/Mead/MINDSELF.HTML. Acesso em: 6 nov. 2003. 